\title{
THE ORIGIN OF THE EFFERENT PROJEGTIONS FROM THE AMYGDALOID COMPLEX TO THE PREOPTIC AREA OF THE RAT, STUDIED BY THE RETROGRADE TRANSPORT OF HORSERADISH PEROXIDASE (HRP)
}

\author{
Haruo KinOShitA, Hiroshi KIMURA*, Toshihiro MAEDA* \\ AND YASUHIKo IBATA \\ Department of Anatomy, Kyoto Prefectural Universiry of Medicine, Kyoto 602 \\ and Department of Anatomy*, Shiga University \\ of Medical Science, Otsu 520-21
}

Received for publication November 16, 1978

\begin{abstract}
The originating neurons of the ipsilateral efferent fiber connections from the amygdaloid complex to the preoptic area of the rat were revealed by the retrograde transport of horseradish peroxidase (HRP). The origin of the efferents from the amygdaloid complex to the preoptic area are the neurons in the central and medial nuclei. The cortical nucleus and other nuclei of the amygdaloid complex could not be ascertained as the origins of these efferent fibers in the present study.
\end{abstract}

The significant role of the amygdaloid complex in the release of gonadotropin has been studied by several investigators $(4,7,12,16,23)$, and it is generally accepted that the impulses from the amygdaloid complex which trigger ovulation $(3,13,14)$ may be transmitted to the preoptic area $(10,24)$ passing through the stria terminalis (25), and accelerating the release of LH-RH (11) which is mainly produced in the neurons in the preoptic area (2).

According to many studies, anatomically, the amygdalofugal fibers have connections not only with the preoptic area, but also with other regions $(1,5,6,8,17,18$, 20, 21, 22). Electrophysiologically, Perkins et al. (19) in 1977 showed the connection between the preoptic area and the amygdaloid complex, and proposed the existence of two types of amygdaloid inputs, direct and indirect, and raised question whether the amygdaloid inputs did in fact have synapses with neurons in the preoptic area which were responsible for triggering the ovulatory surge of LH.

However, all these studies on the connections between the preoptic area and the amygdaloid complex have been made using degenerating methods $(1,5,6,8,17$, $18,20,21,22$ ) or electrophysiological techniques (19), and the neurons in the amygdaloid complex which send their efferents to the preoptic area have not been specifically determined.

In the present study, therefore, retrograde transport of horseradish peroxidase

* This study was supported in part by grants from the Ministry of Education, Japan (Nos. 222121, 248093). 
(HRP) (15) was used in order to determine the precise origins of the efferent fibers to the preoptic area.

\section{MATERIALS AND METHODS}

Fifteen male adult Wistar rats weighing about $250 \mathrm{~g}$ were anesthetized with Nembutal. From 0.1 to $0.5 \mu \mathrm{l}$ of $50 \%$ horseradish peroxidase (HRP) in saline was then injected into the left medial preoptic area using a microelectrode-like glass tube. The animals were perfused with saline under Nembutal anesthesia $24 \mathrm{hr}$ after injection (10 rats), or $48 \mathrm{hr}$ after the injection (5 rats), and, subsequently perfused with a mixture of $0.1 \%$ paraformaldehyde and $0.1 \%$ glutaraldehyde buffered at $\mathrm{pH} 7.4$ with phosphate. After decapitation and removal, the brains were cut frontally into 3 pieces and soaked in the same fixative for $48 \mathrm{hr}$ prior to transfer into $20 \%$ sucrose solution. Twenty $\mu \mathrm{m}$ frontal serial sections were cut with a cryostat and each section was floated serially on $0.1 \mathrm{M}$ phosphate buffer. Each section was transferred to $0.02 \mathrm{M} \mathrm{3-3'-diaminobenzidine} \mathrm{in} \mathrm{Tris} \mathrm{buffer} \mathrm{with} 0.03 \% \mathrm{H}_{2} \mathrm{O}_{2}$, and $15 \mathrm{~min}$ later placed in $0.1 \mathrm{M}$ phosphate buffer. The sections were mounted on glass slides coated with gelatin, stained with cresyl violet, and examined under a dark-field microscope and an ordinary light microscope.

\section{RESULTS}

Good results were obtained in only 5 animals, all of whom survived for $48 \mathrm{hr}$. Animals with a survival period of $24 \mathrm{hr}$ did not show clear HRP-positive precipitations in any neurons in the amygdaloid complex. In the 5 rats HRP-positive neurons appeared as two cell masses within the ipsilateral amygdaloid complex. These HRP-positive neurons were quite evenly distributed in the central nucleus and in the medial nucleus of the amygdaloid complex (Figs. 1, 2). They were mediumsized and multipolar or fusiform in shape. No HRP-positive neurons could be found in the other nuclei of the ipsilateral amygdaloid complex or in the whole contralateral amygdaloid nuclei, although we cannot exclude the possibility that other nuclei of the ipsilateral amygdaloid complex and contralateral amygdaloid nuclei may show HRP-positive neuronal cell soma if the survival time were longer. No HRP-positive fibers could be demonstrated in the present study.

\section{DISGUSSION}

This study proved the existence of the ipsilateral fiber connection from the amygdaloid complex to the preoptic area, and also that the neurons in the amygdaloid complex which send their efferents to the preoptic area are scattered within, at least, two nuclei of the amygdaloid complex (central and medial nuclei). However, we could not prove in the present study that these amygdalofugal fibers to the preoptic area have direct synapses with the neurons producing LH-RH in the preoptic area.

In 1923, Johnston (9) divided the amygdaloid complex phylogenetically into an older group (central, medial and cortical nuclei and the nucleus of the lateral olfactory tract) and a younger one (lateral and basal nuclei). Our present results 


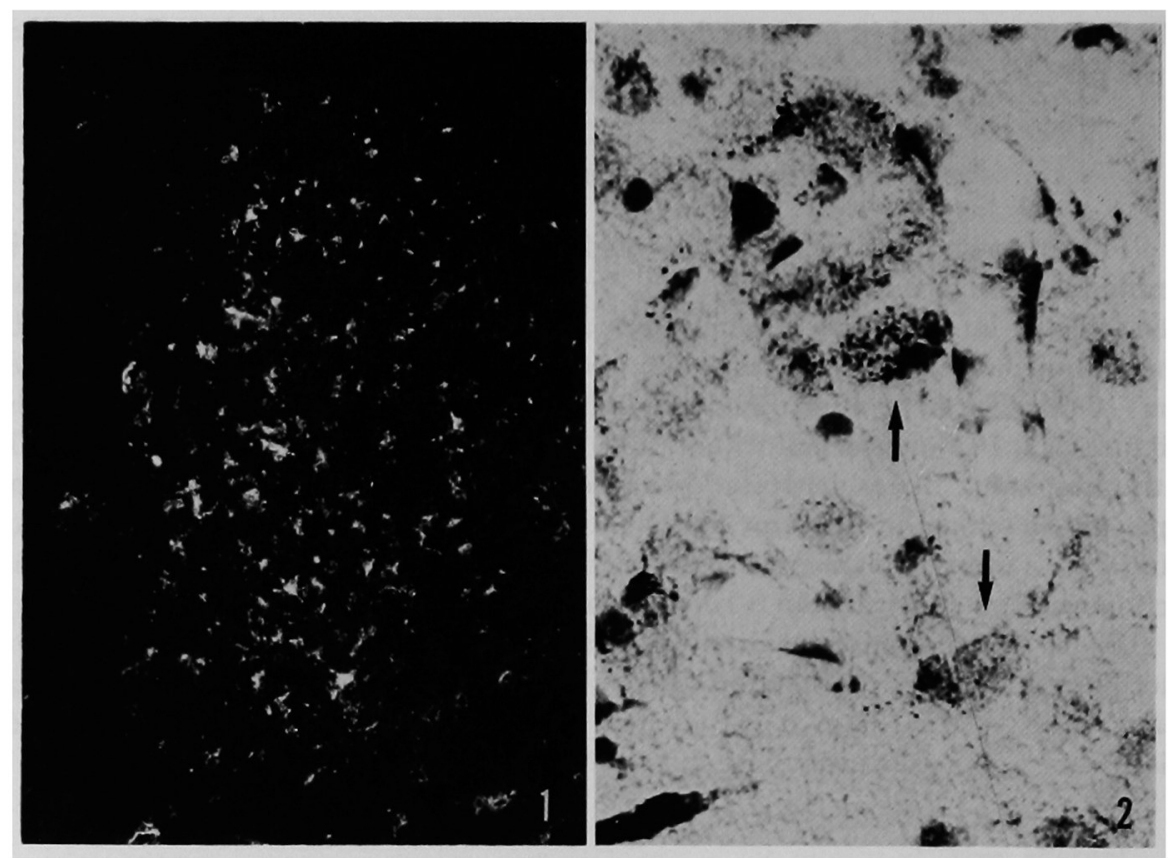

FIG. 1. HRP-positive neurons scattered diffusely within the ipsilateral central nucleus of the amygdaloid complex, observed under a dark-field microscope. $\quad \times 210$

FIG. 2. HRP-positive neurons found in the ipsilateral medial nucleus of the amygdaloid complex, observed under an ordinary light microscope. $\times 1,100$

clarified that the origins of the amygdalofugal fibers to the preoptic area are phylogenetically older portions of the amygdaloid complex. We also partially proved that the corticomedial group of the amygdaloid complex was concerned with ovulation $(13,14)$, but the cortical and basal nuclei which Koikegami $(13,14)$ stimulated in order to observe ovulation in 1954 showed no positive reaction in the present study.

In 1963, Hall (6) speculated that the central nucleus of the amydgaloid complex must be the origin of the efferent fibers to the preoptic area. Our study agrees with her speculation.

In 1961, Nauta (18), using monkeys, described the amygdalofugal fibers and divided them into the diffuse ventral efferent fibers system and the stria terminalis system. The stria terminalis is considered to terminate in the preoptic area $(5,18$, 20, 21, 22) and Perkins et al. (19), in 1977, considered that the direct inputs from the amygdaloid complex pass the stria terminalis. Degenerating axon terminals in the preoptic area in cases of lesions of the stria terminalis have been demonstrated ( 5 , $20,21,22)$. However, it is still uncertain which pathway system the efferent fibers from the neurons in the central and medial nuclei of the amygdaloid complex to the preoptic area utilize, even though the ipsilateral fiber connection between the amygdaloid complex and the preoptic area was clarified in the present study.

Further study is necessary to determine whether the efferent fibers from the 
neurons in the cortico-medial nuclei of the amygdaloid complex terminate with direct synapses on LH-RH producing neurons in the preoptic area.

\section{REFERENCES}

1. Ban, T. and Omukai, F.: Experimental studies of the fiber connections of the amygdaloid nuclei in the rabbit. J. comp. Neur. 113;245-279, 1959.

2. Barry, J., Dubois, M. P. and Poulain, P.: LRF producing cells of the mammalian hypothalamus. A fluorescent antibody study. Z. Zellforsch. 146; 351-366, 1973.

3. Bunn, J. P. and Everett, J. W.: Ovulation in persistent estrous rats after clectrical stimulation of the brain. Proc. Soc. Exp. Biol. 96; 369-371, 1957.

4. Eleftheriou, B. E. and Zolvick, A. J.: Effect of amygdaloid lesions on plasma and pituitary levels of luteinizing hormone. J. Reprod. Fert. 14; 33-37, 1967.

5. Field, P. M.: A quantitative ultrastructural analysis of the distribution of amygdaloid fibers in the preoptic area and the ventromedial hypothalamic nucleus. Exp. Brain Res. 14; 527-538, 1972.

6. Hall, E. A.: Efferent connections of the basal and lateral nuclei of the amygdala in the cat. Amer. J. Anat. 118; 139-151, 1963.

7. Hayward, J. N., Hillard, J. and Sawyer, C. H.: Time of release of pituitary gonadotropin induced by electrical stimulation of the rabbit brain. Endocrinology 74; 108-113, 1964.

8. Ishikawa, I., Kawamura, S. and Tanaka, O.: An experimental study on the efferent connections of the amygdaloid complex in the cat. Actn Med. Okayama 23; 519-539, 1969.

9. Johnston, J. B.: The evolution of the forebrain. J. comp. Neur. 35; 337-481, 1923.

10. Kawakami, M. and Terasawa, E.: A possible role of hippocampus and amygdala in the androgenized rat: Effect of electrical or electrochemical stimulation of the brain on gonadotropin secretion. Endocrinol. Japon. 16; 349-358, 1972.

11. Kawakami, M. and Terasawa, E.: Acute effect of neural deafferentation of timing of gonadotropin secretion before proestrus in the female rat. Endocrinol. Japon. 19; 449-459, 1972.

12. Kawakami, M. and Terasawa, E.: Role of limbic-forebrain structures on reproductive cycles. In Biological Rhythm in Neuroendocrine Activity, ed. by Kawakami., Igaku-Shoin, Tokyo, 1974, p. $197-219$.

13. Koikegami, H., Yamada, T. and Usui, K.: Stimulation of amygdaloid nuclei and periamygdaloid cortex with special reference to its effects on uterine movements and ovulation. Folia Psychial. Neurol. Japon. 8; 7-31, 1954.

14. Koikegami, H.: The Limbic and Paralimbic Systems of the Brain. Acta Anatomica Niigata'ensia Sectionis Anatomicae L'nicersitatis Niigata'ensis 52; 48, 1971.

15. Kristensson, $\mathbf{K}$. and Olsson, $Y^{\prime}$ : Retrograde axonal transport of protein. Brain Research 29; 363-365, 1971.

16. Lawton, I. E. and Sawyer, C. H.: Role of amygdala in regulating LH secretion in the adult female rat. Anat. J. Physiol. 218; 622-626, 1970.

17. Leonard, C. M. and Scott, J. W.: Origins and distribution of amygdalofugal pathways in the rat. An experimental neuroanatomical study. J. comp. Neur. 141;313-330, 1971.

18. Nauta, W. J. H.: Fiber degeneration following lesions of the amygdaloid complex in the monkey. J. Anat. 95; 4, 515-531, 1961.

19. Perkins, M. N.. Demaine, C. and Whitehead, S. A.: Electrophysiological and pharmacological studies of the amygdalo-hypothalamic connections in the rat. Neuroendocrinology 23; 202-211, 1977.

20. Raisman, G.: Evaluation of the basic pattern of connections between the limbic system and the hypothalamus. Amer. J. Anat. 129; 197-202, 1970.

21. Raisman, G. and Field, P. M.: Sexual dimorphism in the preoptic area of the rat. Science 173; 731-733, 1971. 
22. Raisman, G. and Field, P. M.: Sexual dimorphism in the neuropil of the preoptic area of the rat and its dependence on neonatal androgens. Brain Research 54; 1-29, 1973.

23. Velasco, M. E. and Taleisnik, S.: Release of gonadotropins induced by amygdaloid stimulation in the rat. Endocrinology $84 ; 132-139,1969$.

24. Velasco, M. E. and Taleisnik, S.: Effects of the interruption of amygdaloid and hippocampal afferents to the medial hypothalamus on gonadotropin release. J. Endocrinol. $51 ; 41-55,1971$.

25. Zigmond, R. E. and McEwen, B. S.: Selective retention of estradiol by cell nuclei in specific brain regions in the ovariectomized rat. J. Neurochem. 17;889-899, 1970. 